Journal of Telenursing (JOTING)

Volume 2, Nomor 1, Juni 2020

e-ISSN: 2684-8988

p-ISSN: 2684-8996

DOI: https://doi.org/10.31539/joting.v2i1.1191

\title{
PEMBERDAYAAN KADER CILIK DALAM PENINGKATAN PENGETAHUAN, SIKAP DAN PERILAKU JAJAN ANAK SEKOLAH
}

\author{
Oslida Martony \\ Politeknik Kesehatan Kementerian Kesehatan Medan \\ oslida64@gmail.com
}

\begin{abstract}
ABSTRAK
Penelitian ini bertujuan untuk mengetahui pengetahuan, sikap dan perilaku jajan anak sekolah sebelum dan sesudah di berikan penyuluhan terkait pemberdayaan kader di sekolah di SD Muhammadiyah Lubuk Pakam. Metode penelitian ini adalah penelitian korelatif dengan menggunakan desain Cross Sectional. Hasil uji statisitik menunjukkan bahwa nilai $p=0,00<0,05$, berarti ada perbedaan yang signifikan antara pengetahuan, sikap dan perilaku jajan siswa Muhammadiyah dalam memilih makanan jajanan sehat dan makanan jajanan yang mengandung bahan berbahaya sesudah pemberdayaan oleh kader cilik. Simpulan, metode penyuluhan sangat berpengaruh secara signifikan terhadap peningkatan pengetahuan, sikap dan prilaku jajan anak sekolah di SD Muhammadiyah Lubuk Pakam.
\end{abstract}

Kata Kunci : Jajan Anak Sekolah, Kader Cilik, Pengetahuan, Prilaku, Sikap

\section{ABSTRACT}

This study aims to determine the knowledge, attitudes, and behavior of school children snacks before and after counseling related to the empowerment of cadres in schools at Muhammadiyah Lubuk Pakam Elementary School. This research method is a correlative study using a cross-sectional design. The results of the static test show that the value of $p=$ $0.00<0.05$ means that there are significant differences between the knowledge, attitudes, and behavior of Muhammadiyah students' snacks in choosing healthy meals and snacks that contain hazardous ingredients after empowerment by young cadres, In conclusion, the counseling method is very influential in significantly increasing the knowledge, attitudes, and behavior of school children at SD Muhammadiyah Lubuk Pakam.

Keywords: Snack for School Children, Young Cadres, Knowledge, Behavior, Attitude

\section{PENDAHULUAN}

Usia sekolah merupakan salah satu kelompok usia yang memerlukan perhatian khusus dari orang tua dan masyarakat, terutama dalam asupan gizi. Pada masa usia sekolah anak mengalami masa pertumbuhan. Pertumbuhan pada masa anak mengalami perbedaan yang bervariasi sesuai dengan bertambahnya usia anak (Padila et al., 2019; Padila et al., 2019). Tumbuh kembang anak usia sekolah tergantung pada kualitas dan kuantitas nutrisi yang dikonsumsi ataupun yang diberikan orangtua. Begitupun dengan status gizi anak 
dipengaruhi oleh konsumsi jajanan dan aktifitas fisik di sekolah. Perilaku jajan anak tergantung dari kondisi lingkungan sehari-hari dan kebersihan kantin, di mana perilaku jajan ini dipengaruhi teman sebaya sehingga secara tidak langsung keadaan tersebut akan dapat membentuk perilaku jajan sembarangan. Apabila pada masa pertumbuhan ini tingkat konsumsi jajanan tidak terkontrol dengan benar maka dapat mengakibatkan gangguan pencernaan dan berisiko malnutrisi (Devi, 2012).

Berdasarkan Pusat Data Informasi dan Kementerian Kesehatan RI 2015, terjadi peningkatan makanan jajanan tidak sehat di lingkungan sekolah, beberapa makanan mengandung bahan kimia berbahaya yaitu dari 56\% naik menjadi $66 \%$ pada tahun 2011, dan menjadi $76 \%$ pada tahun 2013. Hasil penelitian lain yang dilakukan BPOM Aceh pada tahun 2013 ditemukan sebanyak 2,76\% makanan jajanan yang dijual di lingkungan sekolah yang yang mengandung bahan pengawet (boraks dan formalin,) (BPOM, 2013). Hasil penelitian Depdiknas tahun 2017 tentang sekolah sehat ditemukan sebanyak 84,3\% kantin sekolah belum memenuhi syarat kesehatan, dan masih banyak ditemukan makanan yang tidak memenuhi mutu kebersihan, kesehatan, dan keamanan Adapun jenis pangan jajanan yang tidak memenuhi syarat di Indonesia tahun 2012-2013 yaitu produk minuman es, minuman bewarna, bakso, agar-agar. Penyebab makanan sampel tidak memenuhi syarat antara lain karena menggunakan bahan berbahaya yang dilarang untuk pangan (BPOM, 2014).

Kebiasaan jajan menjadi bagian dari keseharian pada hampir semua kelompok usia, termasuk anak usia sekolah dan remaja, banyaknya faktor-faktor yang dapat mempengaruhi pemilihan makanan jajanan pada anak-anak yaitu pengetahuan, sikap dan perilaku. Hasil penelitian mengenai makanan jajanan pada anak usia Sekolah Dasar yang dilakukan di salah satu Sekolah Dasar Negeri Kota Bandung menyebutkan pemilihan makanan jajanan yang dilakukan oleh siswa di sekolah berada pada pemilihan yang tidak baik dengan presentase pemilihan baik (42,0\%) dan tidak baik (57,3\%) (Iklima, 2017).

Upaya yang dapat dilakukan untuk menghindari anak sekolah dasar dari bahaya makanan jajanan yang tidak sehat adalah dengan memberikan penyuluhan tentang makanan sehat selama masa anak-anak, tidak hanya mencegah beberapa penyebab penyakit utama dan kematian, tetapi juga dapat menurunkan biaya kesehatan dan dapat meningkatkan kualitas hidup manusia (CDC, 2011).

Dari survey awal yang dilakukan di SD Muhammadiyah Lubuk Pakam terdapat dua puluh lima (25) orang kader cilik pengawas jajanan anak sekolah yang siap sebagai tenaga penyuluh, laboratorium dan tim survey, melakukan pemberdayaan kepada teman-teman di kelas 3, 4 dan 5, berdasarkan uraian diatas penelitian ini bertujuan untuk mengetahui pemberdayaan kader cilik dalam peningkatan pengetahuan, sikap dan perilaku jajan anak sekolah sebelum dan sesudah diberikan penyuluhan.

\section{METODE PENELITIAN}

Penelitian ini adalah penelitian kuantitatif dengan menggunakan desain quasi eksperimen with pre test dan post test design. Pengukuran dilakukan sebanyak dua kali, yaitu sebelum diberikan intervensi dan setelah diberikan intervensi dengan masing-masing pertemuan menghabiskan waktu kurang lebih 30 menit. Teknik pengambilan sampel menggunakan total random sampling. Sampel pada penelitian ini adalah 41 yaitu anak kelas 4,5 dan 6. Pelaksanaan penelitian dilakukan di SD Muhammadiyah Lubuk Pakam 
pada bulan November-Desember 2015 dengan memberikan intervensi berupa jajanan sehat. Metode pengumpulan data pada penelitian ini adalah pengisian kuesioner oleh siswa pada saat pre test dan post test. Untuk mendapatkan data pengetahuan, sikap dan perilaku makanan jajanan kemudian dilakukan pengolahan data meliputi editing, coding, entry dan cleaning setelah dilakukan perhitungan, masuk tabulasi data, dilanjutkan pengujian kenormalan data, dilakukan uji mann whitney untuk mendapatkan nilai p_valuenya.

\section{HASIL PENELITIAN}

Dampak pemberdayaan oleh kader cilik pengawas jajanan anak sekolah kepada siswa-siswa SD Muhammadiyah Lubuk Pakam, dimana kader cilik pengawas jajanan anak sekolah yang sudah terbentuk berdampak positif bagi siswa-siswa SD Muhammadiyah. Dua puluh lima (25) orang kader cilik pengawas jajanan anak sekolah yang siap sebagai tenaga penyuluh, laboratorium dan tim survey, melakukan pemberdayaan kepada temanteman di kelas 3, 4 dan 5.

Tabel. 1

Jadwal Penyuluhan Kelompok di Kelas

\begin{tabular}{|c|c|c|c|}
\hline No & Kelas & Kelompok & Tanggal Penyuluhan \\
\hline \multirow[t]{3}{*}{1} & 3 & 1 & 18 Nofember 2015 \\
\hline & 4 & 2 & \\
\hline & 5 & 3 & \\
\hline \multirow[t]{3}{*}{2} & 3 & 4 & 25 November 2015 \\
\hline & 4 & 5 & \\
\hline & 5 & 1 & \\
\hline \multirow[t]{3}{*}{3} & 3 & 2 & 02 Desember 2015 \\
\hline & 4 & 3 & \\
\hline & 5 & 4 & \\
\hline \multirow[t]{3}{*}{4} & 3 & 5 & 09 Desember 2015 \\
\hline & 4 & 1 & \\
\hline & 5 & 2 & \\
\hline \multirow[t]{3}{*}{5} & 3 & 3 & 16 Desember 2015 \\
\hline & 4 & 4 & \\
\hline & 5 & 5 & \\
\hline
\end{tabular}

Berdasarkan tabel 1 pemberdayaan dilakukan oleh 5 orang kader cilik yang terbaik melakukan penyuluhan pada upacara bendera. Hari Senin di lapangan pada upacara bendera yang dilakukan secara bergantian yang dimulai pada tanggal 16 November 2015 di sampaikan oleh Abdul Malik, tanggal 23 November 2015 disampaikan oleh Afrizil Ilmi dengan materi yang sama, pada tanggal 30 November 2015 di sampaikan Fadlan Wafi, pada tanggal 16 Desember 2015 disampaikan Putri dan pada tanggal 14 Desember 2015 disampaikan Tia Amanda materi penyuluhan dengan baik. 
Tabel. 2

Hasil Pre Test dan Post Test Siswa SD Muhammadiyah

\begin{tabular}{|c|c|c|c|c|c|c|c|}
\hline $\begin{array}{l}\mathrm{N} \\
\mathrm{O}\end{array}$ & Nama & $\begin{array}{l}\text { Pre-Test } \\
\text { Pengetahuan }\end{array}$ & $\begin{array}{l}\text { Post-Test } \\
\text { Pengetahuan }\end{array}$ & $\begin{array}{l}\text { Pre-Test } \\
\text { sikap }\end{array}$ & $\begin{array}{l}\text { Post-Test } \\
\text { sikap }\end{array}$ & $\begin{array}{l}\text { Pre-Test } \\
\text { Tindakan }\end{array}$ & $\begin{array}{l}\text { Post-Test } \\
\text { Tindakan }\end{array}$ \\
\hline 1 & $\begin{array}{l}\text { Yessi } \\
\text { Tanjung } \\
\text { Rusli }\end{array}$ & 40 & 85 & 40 & 86.7 & 46.7 & 86.7 \\
\hline 2 & Sahputra & 35 & 90 & 33.3 & 80 & 33.3 & 86.7 \\
\hline 3 & $\begin{array}{l}\text { Aksay } \\
\text { Muh. }\end{array}$ & 45 & 95 & 40 & 80 & 40 & 60 \\
\hline 4 & $\begin{array}{l}\text { Kurniawan } \\
\text { Nabilla }\end{array}$ & 45 & 90 & 33.3 & 66.7 & 40 & 93.3 \\
\hline 5 & Risna & 45 & 90 & 46.7 & 60 & 46.7 & 86.7 \\
\hline 6 & $\begin{array}{l}\text { Muh. Fawan } \\
\text { Dinda }\end{array}$ & 40 & 85 & 46.7 & 66.7 & 46.7 & 86.7 \\
\hline 7 & $\begin{array}{l}\text { Azwani } \\
\text { Bayu }\end{array}$ & 45 & 95 & 26.7 & 73.3 & 53.3 & 60 \\
\hline 8 & $\begin{array}{l}\text { Handoko S } \\
\text { M.Aidil }\end{array}$ & 45 & 95 & 33.3 & 66.7 & 33.3 & 93.3 \\
\hline 9 & Sahputra & 35 & 95 & 33.3 & 60 & 46.7 & 86.7 \\
\hline 10 & Hafiz Akram & 45 & 95 & 46.7 & 60 & 46.7 & 60 \\
\hline 11 & $\begin{array}{l}\text { M.Rahim } \\
\text { Pratama } \\
\text { M.Rahamat }\end{array}$ & 45 & 95 & 33.3 & 66.7 & 53.3 & 93.3 \\
\hline 12 & $\begin{array}{l}\text { Hidayat } \\
\text { Murni Indah }\end{array}$ & 35 & 85 & 40 & 60 & 33.3 & 66.7 \\
\hline 13 & $\begin{array}{l}\text { Yani N } \\
\text { Wika }\end{array}$ & 40 & 80 & 33.3 & 53.3 & 46.7 & 60 \\
\hline 14 & Amanda & 45 & 95 & 46.7 & 80 & 46.7 & 93.3 \\
\hline 15 & Nur Azizah & 40 & 95 & 40 & 80 & 33.3 & 80 \\
\hline 16 & $\begin{array}{l}\text { Muh. Hafidz } \\
\text { Nabila Dwi }\end{array}$ & 45 & 95 & 33.3 & 80 & 40 & 60 \\
\hline 17 & Salwa & 45 & 90 & 40 & 86.7 & 40 & 93.3 \\
\hline 18 & $\begin{array}{l}\text { Beby } \\
\text { Andra Yopi }\end{array}$ & 45 & 80 & 46.7 & 66.7 & 46.7 & 86.7 \\
\hline 19 & Darmawan & 35 & 90 & 40 & 66.7 & 46.7 & 60 \\
\hline 20 & Dana Azahra & 45 & 95 & 33.3 & 60 & 53.3 & 66.7 \\
\hline 21 & $\begin{array}{l}\text { Aida Fitriani } \\
\text { Fadel }\end{array}$ & 40 & 95 & 40 & 86.7 & 33.3 & 86.7 \\
\hline 22 & $\begin{array}{l}\text { Muhammad } \\
\text { Arthur Dwi }\end{array}$ & 45 & 90 & 33.3 & 80 & 46.7 & 80 \\
\hline 23 & Aeldi & 35 & 85 & 40 & 60 & 40 & 73.3 \\
\hline 24 & $\begin{array}{l}\text { Cut Aulia } \\
\text { Kevin } \\
\text { Agatha }\end{array}$ & 45 & 95 & 33.3 & 86.7 & 53.3 & 60 \\
\hline 25 & $\begin{array}{l}\text { Ginting } \\
\text { M. Agung }\end{array}$ & 45 & 90 & 40 & 60 & 33.3 & 86.7 \\
\hline 26 & Pratama & 45 & 95 & 46.7 & 86.7 & 46.7 & 86.7 \\
\hline
\end{tabular}




\begin{tabular}{|c|c|c|c|c|c|c|c|}
\hline 27 & $\begin{array}{l}\text { M.Rasya } \\
\text { Ramadhan }\end{array}$ & 40 & 90 & 26.7 & 73.3 & 46.7 & 60 \\
\hline 28 & $\begin{array}{l}\text { Ayu } \\
\text { Khairunisa } \\
\text { Faris Ahmad }\end{array}$ & 45 & 85 & 33.3 & 60 & 33.3 & 86.7 \\
\hline 29 & $\begin{array}{l}\text { Assyukri } \\
\text { Bima }\end{array}$ & 45 & 90 & 33.3 & 60 & 40 & 60 \\
\hline 30 & Pradana & 35 & 90 & 46.7 & 86.7 & 40 & 66.7 \\
\hline 31 & $\begin{array}{l}\text { Keiko Ryian } \\
\text { Tirta } \\
\text { Rahmad } \\
\text { Akbar }\end{array}$ & 45 & 85 & 33.3 & 73.3 & 46.7 & 60 \\
\hline 32 & $\begin{array}{l}\text { Aditya } \\
\text { Sabila }\end{array}$ & 45 & 90 & 40 & 86.7 & 46.7 & 66.7 \\
\hline 33 & $\begin{array}{l}\text { Cairunicha } \\
\text { M.Fahri }\end{array}$ & 35 & 95 & 33.3 & 80 & 53.3 & 60 \\
\hline 34 & $\begin{array}{l}\text { Alkahfi } \\
\text { Ahmad }\end{array}$ & 40 & 85 & 46.7 & 80 & 33.3 & 60 \\
\hline 35 & $\begin{array}{l}\text { Ferdiansyah } \\
\text { M.Farel }\end{array}$ & 45 & 90 & 40 & 66.7 & 46.7 & 86.7 \\
\hline 36 & $\begin{array}{l}\text { Gustiar } \\
\text { Farel }\end{array}$ & 40 & 90 & 40 & 86.7 & 46.7 & 80 \\
\hline 37 & $\begin{array}{l}\text { Fahrezi } \\
\text { M. }\end{array}$ & 45 & 85 & 46.7 & 66.7 & 53.3 & 60 \\
\hline 38 & Ferdiasyah & 45 & 85 & 40 & 66.7 & 33.3 & 80 \\
\hline 39 & $\begin{array}{l}\text { Mey Hari } \\
\text { Ilham Al }\end{array}$ & 40 & 90 & 46.7 & 53.3 & 46.7 & 60 \\
\hline 40 & $\begin{array}{l}\text { Hafiz } \\
\text { Dwi Ayu }\end{array}$ & 45 & 85 & 40 & 66.7 & 46.7 & 80 \\
\hline 41 & Pratiwi & 50 & 95 & 46.7 & 93.3 & 53.3 & 60 \\
\hline
\end{tabular}

Keterangan : Nilai : 0 - 100

Berdasarkan data nilai pre test dan post test di atas maka secara rinci hasil nilai ratarata pre-test dan post test dapat dilihat pada Tabel 4.13 dibawah ini.

Tabel. 3

Perbedaan Nilai Pengetahuan, Sikap, dan Tindakan Pre- test dan Post-Test pada siswa SD Muhammadiyah

\begin{tabular}{|c|c|c|c|c|c|c|c|}
\hline \multirow[t]{2}{*}{ No } & \multirow[t]{2}{*}{ Peri Laku } & \multirow[t]{2}{*}{$\mathrm{N}$} & \multirow{2}{*}{$\begin{array}{l}\text { Nilai } \\
\text { Rerata }\end{array}$} & \multicolumn{2}{|c|}{ Nilai } & \multirow[t]{2}{*}{ Std. Deviasi } & \multirow[t]{2}{*}{ Nilai $p$} \\
\hline & & & & Min & Max & & \\
\hline \multirow[t]{3}{*}{1.} & Pengetahuan & & & & & & \multirow{3}{*}{0,000} \\
\hline & Post Test I & 41 & 42,32 & 35,00 & 50,00 & 4,046 & \\
\hline & Post Test II & 41 & 90,12 & 80,00 & 95,00 & 4,540 & \\
\hline \multirow[t]{3}{*}{2.} & Sikap & & & & & & \multirow{3}{*}{0,000} \\
\hline & Post Test I & 41 & 38,85 & 27,00 & 47,00 & 6,142 & \\
\hline & Post Test II & 41 & 72,29 & 53,00 & 93,00 & 11,203 & \\
\hline \multirow[t]{3}{*}{3.} & Tindakan & & & & & & \multirow{3}{*}{0,000} \\
\hline & Post Test I & 41 & 43,76 & 33,00 & 53,00 & 6,942 & \\
\hline & Post Test II & 41 & 74,71 & 60,00 & 93,00 & 13,191 & \\
\hline
\end{tabular}


Data dari tabel 3 diatas dapat di gambarkan secara rinci nilai rata-rata perbedaaan pengetahuan pre test dan post test.

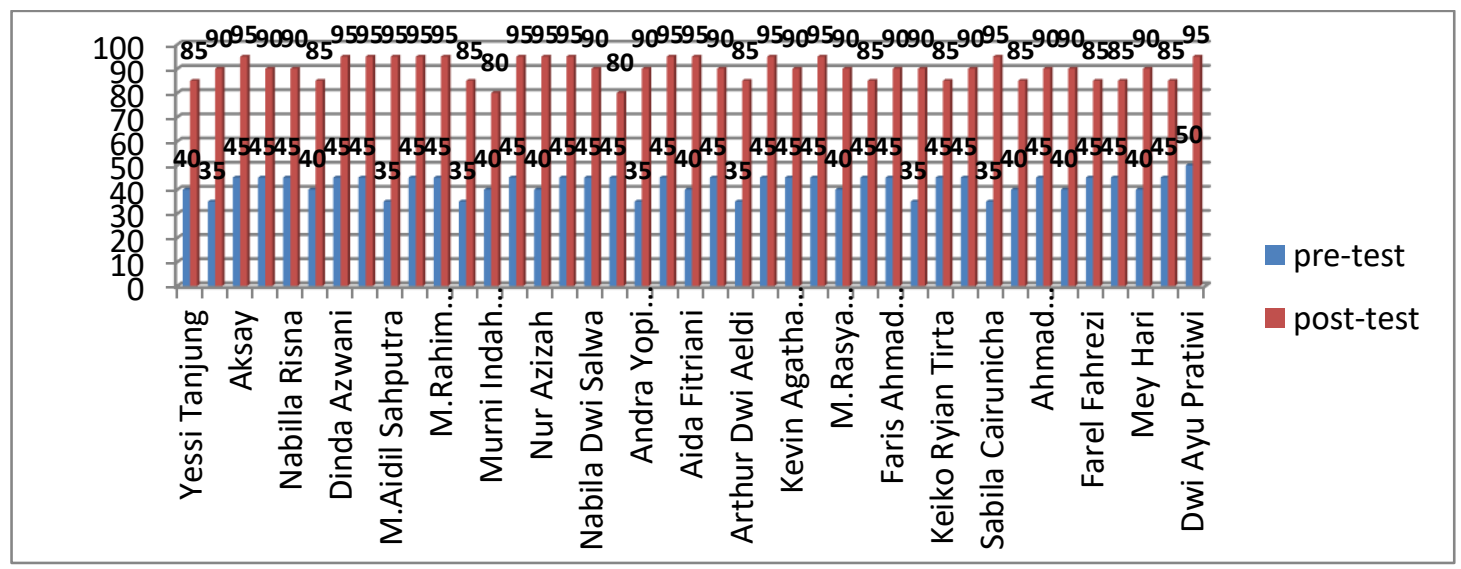

Gambar. 1

Diagram Hasil Perbedaan Nilai Pengetahuan Pre Test dan Post Test Siswa SD Muhammadiyah

Berdasarkan data gambar 1 diatas dapat dilihat, adanya peningkatan pengetahuan siswa SD Muhammadiyah dari nilai rata-rata pada pre test dengan nilai rata-rata 42,32 setelah dilakukan intervensi oleh kader cilik pengawas jajanan anak sekolah terjadi peningkatan nilai rata-rata pengetahuan siswa SD Muhammadiyah meningkat menjadi 90,12 dengan nilai terendah pada saat pre test 35 dan nilai tertinggi 50 sedangkan nilai terendah pada saat post test 80 dan nilai tertinggi 95 , untuk mengetahui perbedaan rata-rata nilai pengetahuan siswa Muhammadiyah pada pre test dan post test dilakukan uji $\mathrm{T}$ Dependen pada nilai alpha 5\%. Hasil uji statistk menyimpulkan ada perbedaan yang signifikan dengan nilai $p=0,00<0,05$, berarti ada perbedaan yang signifikan pengtahuan siswa Muhammadiyah dalam memilih makanan jajanan sehat dan makanan jajanan yang mengandung bahan berbahaya sesudah pemberdayaan oleh kader cilik

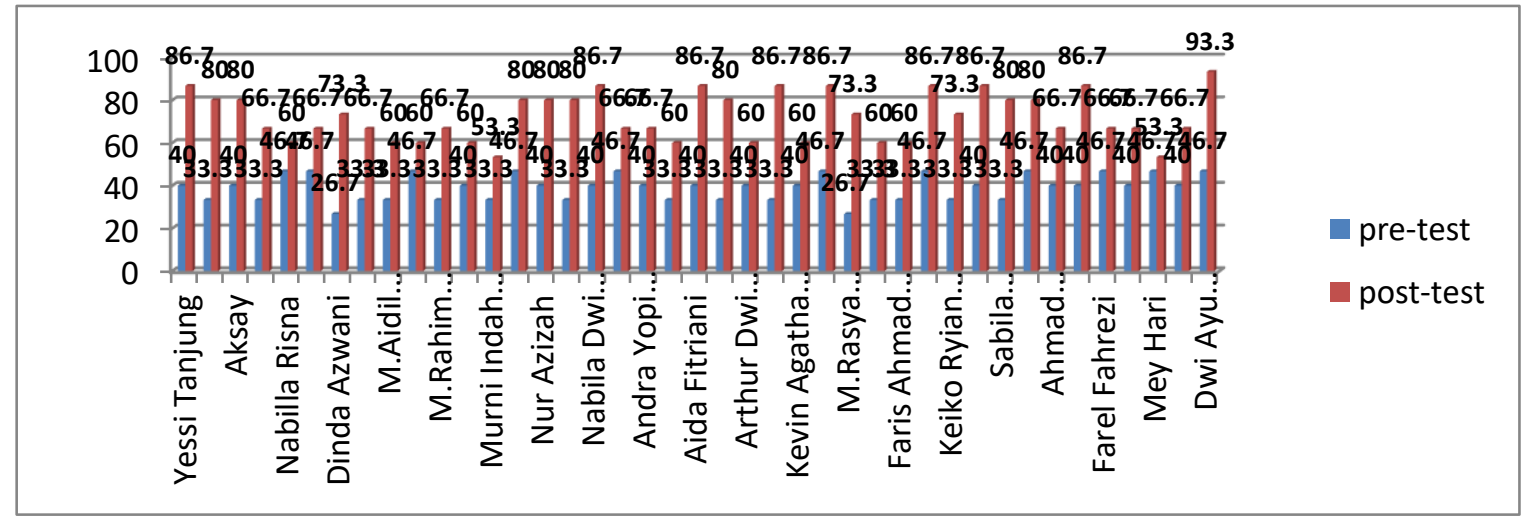

Gambar. 3

Diagram Hasil Perbedaan Nilai Sikap Pre Test dan Post Test Siswa SD Muhammadiyah 
Berdasarkan data gambar diatas dapat dilihat, adanya peningkatan sikap siswa SD Muhammadiyah dari nilai rata-rata pada pre test dengan nilai rata-rata 38,85 setelah dilakukan intervensi maka terjadi peningkatan nilai rata-rata sikap siswa SD Muhammadiyah meningkat menjadi 72,29 dengan nilai terendah pada saat pre tes 27 dan nilai tertinggi 47 sedangkan nilai terendah saat post test 53 dan nilai tertinggi 93, untuk mengetahui perbedaan rata-rata nilai sikap siswa Muhammadiyah pada pre test dan pos test dilakukan uji $\mathrm{T}$ Dependen pada nilai alpha 5\%. Hasil uji statistk menyimpulkan ada perbedaan yang signifikan dengan nilai $p=0,00<0,05$, berarti ada perbedaan yang signifikan sikap siswa Muhammadiyah dalam memilih makanan jajanan sehat dan makanan jajanan yang mengandung bahan berbahaya sesudah pemberdayaan oleh kader cilik,

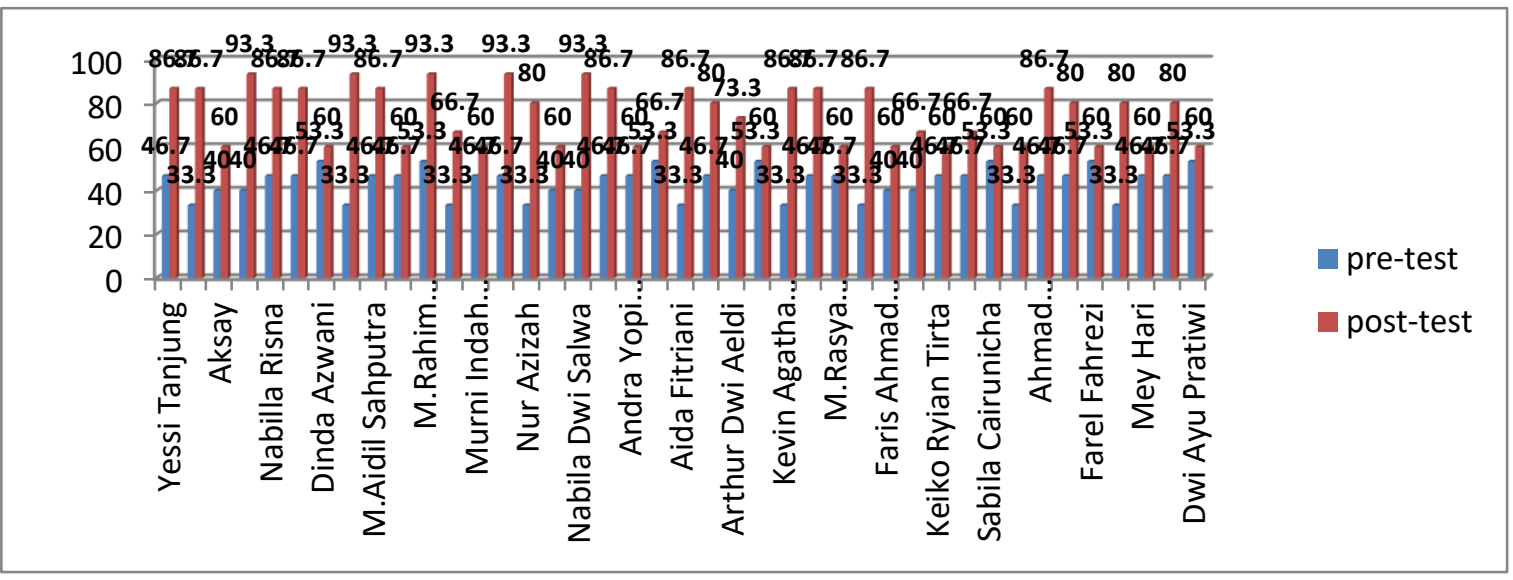

Gambar. 4

Diagram Hasil Perbedaan Nilai Tindakan Pre Test dan Post Test Siswa SD Muhammadiyah

Berdasarkan data gambar diatas dapat dilihat, adanya peningkatan tindakan pada siswa SD Muhammadiyah dari nilai rata-rata pada pre test dengan nilai rata-rata 43,76 setelah dilakukan intervensi maka terjadi peningkatan nilai rata-rata tindakan siswa SD Muhammadiyah meningkat menjadi 74,71 dengan nilai terendah pada saat pre test 33 dan nilai tertinggi 53 sedangkan nilai terendah pada saat post test 60 dan nilai tertinggi 93 . Untuk mengetahui perbedaan rata-rata nilai tindakan siswa Muhammadiyah pada pre test dan post test dilakukan uji $\mathrm{T}$ dependen pada nilai alpha 5\%. Hasil uji statistk menyimpulkan ada perbedaan yang signifikan dengan nilai $p=0,00<0,05$, berarti ada perbedaan yang signifikan tindakan siswa Muhammadiyah dalam memilih makanan jajanan sehat dan makanan jajanan yang mengandung bahan berbahaya sesudah pemberdayaan oleh kader cilik.

\section{PEMBAHASAN}

Berdasarkan hasil penelitian menunjukkan adanya peningkatan pengetahuan siswa SD Muhammadiyah dari nilai rata-rata pada pre test dengan nilai rata-rata 42,32 setelah dilakukan intervensi oleh kader cilik pengawas jajanan anak sekolah terjadi peningkatan nilai rata-rata pengetahuan siswa SD Muhammadiyah meningkat menjadi 90,12 dengan nilai terendah pada saat pre test 35 dan nilai tertinggi 50 sedangkan nilai terendah pada saat 
post test 80 dan nilai tertinggi 95, untuk mengetahui perbedaan rata-rata nilai pengetahuan siswa Muhammadiyah pada pre test dan post test dilakukan uji $\mathrm{T}$ dependen pada nilai alpha $5 \%$. Hasil uji statistik menyimpulkan ada perbedaan yang signifikan dengan nilai $p=0,00$ $<0,05$, berarti ada perbedaan yang signifikan pengetahuan siswa Muhammadiyah dalam memilih makanan jajanan sehat dan makanan jajanan yang mengandung bahan berbahaya sesudah pemberdayaan oleh kader cilik.

Safriana (2012) mengatakan baiknya status kesehatan apabila anak dapat mengkonsumsi makanan yang sehat dan higienis. Seseorang yang memiliki pengetahuan yang baik dalam pemilihan makanan jajanan memungkinkan anak tersebut untuk lebih selektif dalam memilih jajanan yang sehat. Selain itu dengan baiknya pengetahuan siswa/i akan membuat anak lebih sadar menjaga kesehatan tubuh dengan menjaga pola makan yang sehat. Dengan makanan jajanan yang sehat akan berdampak pada baiknya status kesehatan siswa tersebut. Siswa yang memiliki status kesehatan yang baik akan terhindar dari berbagai penyakit (Febriawati et al., 2018). Adapun dampak mengkonsumsi jajanan yang tidak sehat yaitu dapat terserang penyakit diare, mual, muntah, pusing, dan timbul penyakitpenyakit lainnya (Safriana, 2012).

Penelitian ini sejalan dengan penelitian yang dilakukan oleh Yulianto et al., (2013) di SDN Wilayah Kelurahan Sukajaya Palembang dengan jumlah responden 153 siswa/i yang menyatakan bahwa terdapat hubungan pengetahuan jajanan dengan status kesehatan $(\mathrm{p}<$ 0,000). Semakin baik tingkat pengetahuan terhadap pemilihan makanan jajanan pada siswa/i, maka status kesehatan akan semakin baik juga.

Semito (2014) mengatakan bahwa dengan sikap mendukung yang dimiliki anak akan mampu menerapkan hidup yang sehat dan terhindar dari berbagai penyakit yang dapat ditimbulkan dari makanan jajanan yang tidak higienis. Memiliki sikap yang mendukung dalam pemilihan makanan jajanan akan membuat status kesehatan anak lebih baik dan anak tidak pernah sakit. Sedangkan jika anak memiliki sikap yang tidak mendukung maka mereka jajan disembarangan tempat, sehingga dapat memicu timbulnya berbagai macam penyakit berbahaya dari makanan jajanan yang tidak sehat (Semito, 2014).

Dari hasil penelitian ini adanya peningkatan sikap siswa SD Muhammadiyah dari nilai rata-rata pada pre test dengan nilai rata-rata 38,85 setelah dilakukan intervensi maka terjadi peningkatan nilai rata-rata sikap siswa SD Muhammadiyah meningkat menjadi 72,29 dengan nilai terendah pada saat pre tes 27 dan nilai tertinggi 47 sedangkan nilai terendah saat post test 53 dan nilai tertinggi 93, untuk mengetahui perbedaan rata-rata nilai sikap siswa Muhammadiyah pada pre test dan pos test dilakukan uji T Dependen pada nilai alpha 5\%. Hasil uji statistik menyimpulkan ada perbedaan yang signifikan dengan nilai $p=$ $0,00<0,05$, berarti ada perbedaan yang signifikan sikap siswa Muhammadiyah dalam memilih makanan jajanan sehat dan makanan jajanan yang mengandung bahan berbahaya sesudah pemberdayaan oleh kader cilik.

Penelitian sebelumnya yang dilakukan oleh Briawan bekerjasama dengan PT Unilever Indonesia terhadap 1.600 anak SD kelas 5 di 8 Provinsi di Indonesia, setelah diberikan edukasi gizi dengan media flipchart, poster dan audio kinetik selama 21 hari terjadi peningkatan jumlah proporsi pengetahuan anak dengan tingkat pengetahuan baik sebesar $16,2 \%$, peningkatan proporsi anak yang memiliki sikap jajanan yang baik sebesar 7,3\%, dan peningkatan proporsi anak dalam praktik memilih jajanan yang baik sebesar 2,7\% (Briawan, 2016). 
Berdasarkan data gambar diatas dapat dilihat, adanya peningkatan Tindakan pada siswa SD Muhammadiyah dari nilai rata-rata pada pre test dengan nilai rata-rata 43,76 setelah dilakukan intervensi maka terjadi peningkatan nilai rata-rata tindakan siswa SD Muhammadiyah meningkat menjadi 74,71 dengan nilai terendah pada saat pre test 33 dan nilai tertinggi 53 sedangkan nilai terendah pada saat post test 60 dan nilai tertinggi 93 . Untuk mengetahui perbedaan rata-rata nilai tindakan siswa Muhammadiyah pada pre test dan post test dilakukan uji $\mathrm{T}$ dependen pada nilai alpha 5\%. Hasil uji statistik menyimpulkan ada perbedaan yang signifikan dengan nilai $p=0,00<0,05$, berarti ada perbedaan yang signifikan tindakan siswa Muhammadiyah dalam memilih makanan jajanan sehat dan makanan jajanan yang mengandung bahan berbahaya sesudah pemberdayaan oleh kader cilik.

Hasil lainnya menunjukkan perilaku anak sebelum dilakukan penyuluhan yaitu sebesar $66,7 \%$ yang mempunyai perilaku yang baik, dan 33,3\% mempunyai perilaku yang cukup. Peningkatan pengetahuan, sikap dan perilaku anak meningkat disebabkan adanya penambahan informasi yang dilakukan kepada anak melalui pendidikan gizi (Ismail, 2018; Febriawati et al., 2018).

\section{SIMPULAN}

Pemberdayaan kader cilik sangat berpengaruh secara signifikan terhadap peningkatan pengetahuan, sikap dan prilaku jajan anak sekolah di SD Muhammadiyah Lubuk Pakam. Semakin baik tingkat pengetahuan, sikap dan perilaku terhadap pemilihan makanan jajanan pada siswa/i, maka status kesehatan akan semakin baik pula.

\section{SARAN}

Saran Teoritis

Diharapkan dapat dijadikan acuan dalam pengembangan intervensi keperawatan khususnya yang berhubungan dengan pengetahuan, sikap dan prilaku dalam menentukan jajanan di sekolah.

\section{Saran Praktik}

\section{Bagi Tempat Penelitian}

Kepada SD lubuk pakam selalu memberikan support terhadap kegiatan kader cilik dalam memberikan penyuluhan jajanan yang sehat agar meningkatkan kembali pengetahuan, sikap dan perilaku siswa/i dalam menentukan jajanan yang dipilih.

\section{Bagi Peneliti Selanjutnya}

Kepada peneliti lain diharapkan dapat melanjutkan penelitian ini dengan menambah variable lainnya yaitu menentukan kriteria jajanan yang sehat agar dapat meningkatkan pengetahuan, sikap dan prilaku setra gizi yang baik dalam jajanan yang sehat. 


\section{DAFTAR PUSTAKA}

BPOM RI. (2013). Jajanan Anak Sekolah. Food Watch Sistem Keamanan Pangan Terpadu, Voll. di peroleh dari http://www.pom.go.id/mobile/index.php/view/b erita /146/ Keamanan. Diakses tanggal 11 mei 2020

BPOM RI. (2014). Food Safety Management Disekolah. Diperoleh dari https://hfis.wo rdpress.com/2014/02/13/food-safetymanagement-di-sekolah/ diakses pada 12 april 2020

Briawan, D. (2016). Perubahan Perilaku Perilaku, dan Praktik Jajanan Anak Sekolah Dasar Peserta Program Edukasi Pangan Jajajan. Jurnal Gizi Pangan, 11(3), 201-210. Diakses pada 13 Mei 2020

Centers for Disease Control and Prevention (CDC). (2011). School Health Guidelines to Promote Healthy Eating and Physical Activity. http://www.cdc.gov/ $\mathrm{mmwr} / \mathrm{preview} / \mathrm{mmwr}$ html/rr6005a1.htm. Diakses pada tanggal 13 Mei 2020

Devi, N. (2012). Gizi Anak Sekolah. Jakarta: PT Kompas Media Nusantara

Febriawati, H., Padila, P., \& Anita, B. (2018). Pendidikan Seksual Remaja Melalui Poskesja. Jurnal Pengabdian Masyarakat Bumi Raflesia 1(1), 45-54

Iklima, N. (2017). Gambaran Pemilihan Makanan Jajanan pada Anak Usia Sekolah Dasar. Jurnal Keperawatan BSI, 5(1). Diakses pada 12 mei 2020

Ismail, I., Anshrulloh, A., \& Rejeki, S. (2018). Perbedaan antara Pengetahuan, Sikap dan Perilaku Anak tentang Konsumsi Jajanan Sehat (Sebelum dan Sesudah Penyuluhan) di SD Negeri 4 Poasia Kecamatan Kambu Kota Kendari. J. Sains dan Teknologi Pangan, 3(1), 1036-1051. Diakses pada 13 mei 2020

Padila, P., Andari, F. N., \& Andri, J. (2019). Hasil Skrining Perkembangan Anak Usia Toddler antara DDST dengan SDIDTK. Jurnal Keperawatan Silampari, 3(1), 244256. https://doi.org/10.31539/jks.v3i1.809

Padila, P., Andari, F. N., Harsismanto, J., \& Andri, J. (2019). Tumbuh Kembang Anak Usia Toddler Berbasis Research. Lubuklinggau: Asra

Safriana, S. (2012). Perilaku Pemilihan Jajanan pada Siswa Sekolah Dasar di SDN Garot ke Darul Imarah Kabupaten Aceh Besar. Diperoleh dari http://ejournal.upi.edu/in dex.php/JPKI/article/download/1184/82 9. Diakses pada 12 april 2020

Semito, M. N. L. (2014). Hubungan antara Pengetahuan, Pola Konsumsi Jajanan dan Status Gizi Siswa SDN di Wilayah Kabupaten Cilacap. Diperoleh dari http://eprin ts.uny.ac.id/30698/1/Ninal\%20Natya\%2

Yulianto, Y., Khotimah, N., \& Yusuf, Y. (2013). Identifikasi Zat Pewarna pada Makanan Jajanan, Frekuensi Jajan, Pengetahuan Gizi, dan Hubungan dengan Status Kesehatan dan Status Gizi Murid Sekolah Dasar di Wilayah Kelurahan Sukajaya Palembang 2013. Diperoleh dari http://jurnal.poltekkespalembang.ac.id/ojs/index.php/joh. Diakses pada 23 april 2020 